\title{
The Diagenesis of Sandstone in the Sixth Oil Layer of the Upper Triassic Yanchang Formation in Baibao Area, Ordos Basin
}

\author{
Wei Guo ${ }^{1,2, a^{*}}$ Dexun Liu ${ }^{1,2, b}$ Huaqing Xue ${ }^{1,2, c}$ Xiaobo Li ${ }^{1,2, d}$ \\ ${ }^{1}$ Petrochina Research Institute of Petroleum Exploration \& Development, Langfang, \\ Hebei 065007, China \\ ${ }^{2}$ National Energy Shale Gas Research Development (Experimental) Center, Langfang, \\ Hebei 065007, China \\ apkuguowei69@petrochina.com.cn, ${ }^{\mathrm{b}}$ liudexun@petrochina.com.cn, \\ chuaqingxue@petrochina.com.cn, 'lixiaobo@petrochina.com \\ ${ }^{*}$ corresponding author
}

\begin{abstract}
Keywords: Diagenesis; Reservoirs; Yanchang Formation; Ordos Basin
Abstract. The properties of the reservoir sandstone mainly depend on the sedimentary environment and the diagenesis. The thoroughly research on the diagenesis of the sandstone reservoir in the sixth oil layer of the Upper Triassic Yanchang formation has been one of the core geological problems. The comprehensive analysis shows that the reservoir rock types are mainly fine-grained-powder fine-grained feldspar lithic sandstones and lithic arkoses; rocks have low compositional maturity and medium textural maturity. Sandstone generally experienced strong compaction transformation, mainly mechanical compaction, making the primary pores in sandstones significantly loss. Feldspar etc. often occurs apparent dissolution, and secondary pores widely developed. In addition, the sandstones also experienced late cementation and fracturing. The sandstone reservoirs are in the middle diagenetic stage $\mathrm{B}$ period.
\end{abstract}

\section{Introduction}

The large scale oil exploration in Ordos basin has been carried out for more than 30 years, during which time we have found that the sixth oil layer of the Upper Triassic Yanchang formation (Chang 6 in short) is one of the most important oil layers in Ordos basin, and its newly-found proven crude oil reserves and output both occupy more than 70\% [1] of that of this basin. Baibao area is located in the Midwest of Yishan slope, Ordos's basin. Since industrial oil flow was found in the sixth layer at the end of last century, with the pace of the exploration and the exploitation speeding up, the area has been one of the most significant areas to increase production of the Ordos basin. Past research ${ }^{[2,3]}$ shows that the front edge at Lake Bottom of the delta in the sixth oil layer of the Upper Triassic Yanchang formation in Baibao area slumps and turbidite fans develop, which has been proven peacefully by production practice; and the properties of the reservoir sandstone mainly depend on the sedimentary environment and the diagenesis.

\section{Petrology characteristics}

The main types of reservoir rock in the Chang 6 formation of the Baibao area include fine and powder-fine feldspar lithic sandstone and lithic arkoses in colors of gray, light gray and taupe. The content of quartz in the sandstone of the Chang 6 formation is about $14 \%$ to $35 \%$, in which the mono-crystalline quartz is the main part, and the content of flint is less, and part of it can be seen undulatory extinction. The content of detrital feldspar is about $18 \%$ to $46 \%$, with plagioclase feldspar the main part, orthoclase the less part, and microcline little. The content of debris is about $14 \%$ to $45 \%$, and rally reaches $45 \%$, with mica debris the main part, metamorphic rock debris, sedimentary rock debris and chlorite the less part, and lava debris little. The sandstone particle size mainly is 
ultrafine-fine particle and powder-fine particle, and rally is mid-coarse sandstone. Debris particle mainly is angled shape. Sorting is medium to bad, mainly in linear contact, partly in point contact and concavo-convex contact. Grain supporting types mainly are pore-film and porous cementation. Component maturity is relatively low and textural maturity is medium.

\section{Types and Characteristics of Diagenesis}

The mainly diagenesis types occurred in the sandstone reservoirs of Chang 6 Baibao area are compaction, cementation, fracturing, and dissolution and so on. The diagenesis is complex, and diagenetic phenomenon is rich, both of which have significant impact on the development of porosity in reservoir layers.

\section{Compaction}

In Chang 6 the Upper Triassic Yanchang Formation Baibao Area, the contact between the particles is close, and appears in irregular or stitched contact (Figure 1 (a), 1 (b)). In the reservoirs of this area, it is rare to see quite obvious pressure solution phenomenon, indicating that the main diagenesis is mechanical compaction. Mechanical compaction reduces the number of primary porosity in the reservoir greatly, and makes the rock volume reduced, which is not conducive to the preservation of the pore.

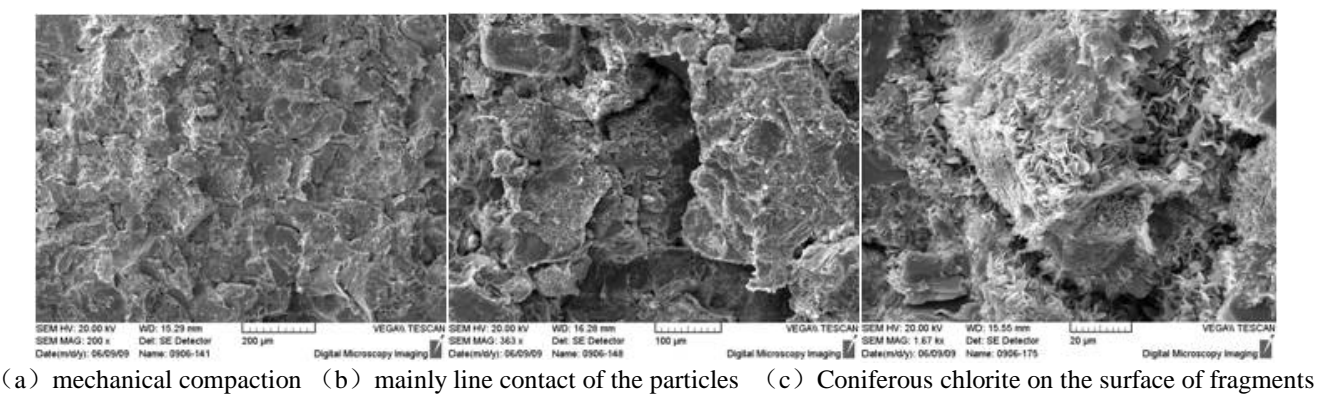

Fig. 1 the compaction and the chlorite membrane on the surface of fragments

By studying the precipitation of clay film widely developed in the Chang 6 oil layer formation of this area, we find the main content is terrigenous clay or early diagenetic clay, with the chlorite the main part, belonging to the early diagenesis product, which is usually formed in a strong hydrodynamic sedimentary environment. Chlorite clay film are mostly round film-like, covering the surface of the particles, increasing the mechanical strength of the rock so that it is able to resist compaction, thereby is conducive to the preservation of porosity between particles(Figure 1 (c)), and leaves space for the late secondary porosity formation.

\section{Cementation}

\section{(1) siliceous cements}

The siliceous cement distributes widely in the study area, but the content is relatively low. The main cementation types are secondary enlargement cementation and pore-filling cementation. $\mathrm{SiO}_{2}$ mainly comes from the following ways: the surface water and groundwater, the clastic rocks British pressure solution, diagenetic transformation of clay minerals such as montmorillonite to kaolinite transformation and so on. Because the above diagenetic phenomena in the study area are less developed, it is not possible to provide substantial material sources for the formation of the siliceous cement, resulting the content of this kind cement is relatively low $(<5 \%)$.

Siliceous cementation is bad for production of secondary porosity. It fills pores, and does not provide soluble substances for the dissolution afterwards, which is an important cause of the poor physical properties of the sandstone.

(2)Clay mineral cements

Chlorite mostly in the shape of fine foliate or fibrous crystals, grows perpendicularly to the surface of the detrital grains or pore throat wall, usually developing into the pore-lining (Figure 2 (a)(b)(c)), and missing at the contact between debris particles. Part of the chlorite film surrounds the entire debris particles (Figure 1 (c)), showing that the chlorite thin film formed at the same time with the 


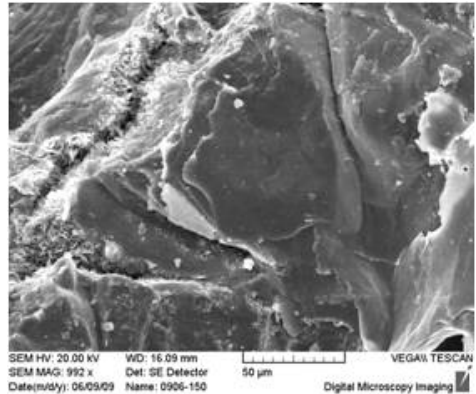

(a) intergranular seams filled by conifer-like chlorite

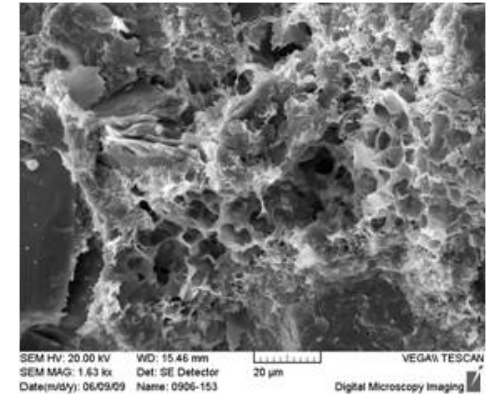

(b) intergranular honeycomb I / S mixed layers

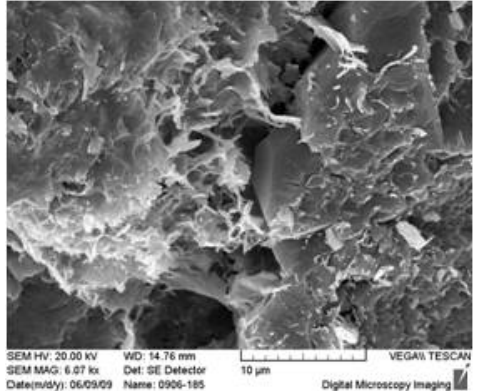

(c) the intergranular film filamentous illite

Fig. 2 cementation of the clay minerals

compaction, or later, as a result of the diagenesis at early stage. In addition, chlorites, in the shape of leaves, are filled in the pores between particles, mostly in the residual holes and partially in the dissolution pores, indicating that this part of chlorites formed in a relatively late time. On the one hand chlorite film fills the native porosity and reduces porosity; on the other hand the formation of the chlorite film hindered the further reaction between pore water and particles, and limited the development of quartz's secondary enlargement, which is conducive to the preservation of primary porosity.

\section{(3) Carbonate cements}

Carbonate cements in the Chang 6 clastic of the study area are very common. Carbonate cements mainly are calcite $(0.04 \%)$, iron calcite $(2.95 \%)$ and iron dolomite $(1.33 \%)$. Observed under microscope in thin sections, calcite and iron calcite is pore filling, and some parts are in polycrystalline cementation. Carbonate cements are produced in different stages of diagenesis, just quiet different in the crystal size and composition.

Such cements have dual effects on the development of the reservoirs: the one hand, carbonate cementation can clog pores, lowering the reservoir quality; on the other hand, the precipitation of cements in reservoirs can play a supporting role, effectively reducing the degree of compaction of the sandstone, creating favorable conditions for the acidic water dissolution and the formation of secondary porosity.

\section{Dissolution}

The dissolution of the sandstone in this area is very common, mainly in a way that the soluble components of clastic dissolute, forming a large number of secondary porosity. Chang 6 sandstone the soluble components in the sandstone of Chang 6 this area are mainly feldspar debris, mud heteroaryl, chlorite rim and cements; the weak solvent components are carbonate and mica; insoluble components are dolomite, calcite and quartz. Reaction dissolution fluid is acidic hydrothermal fluid rich in carbon dioxide; generated secondary porosity is mainly inter-granular dissolved pore, followed by intra-granular dissolved pore.

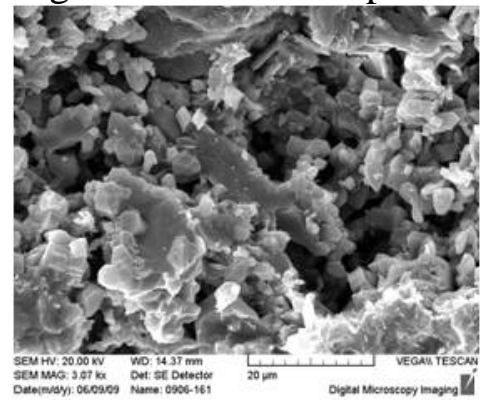

(a) K-feldspar dissolution and authigenic quartz crystal

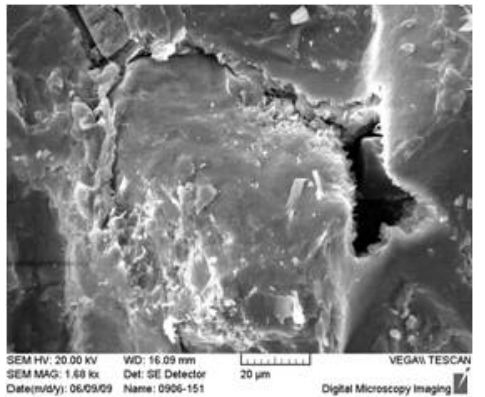

(b) intergranular dissolved pores and grain boundary fractures in dissolved pores

Fig.3 Dissolution

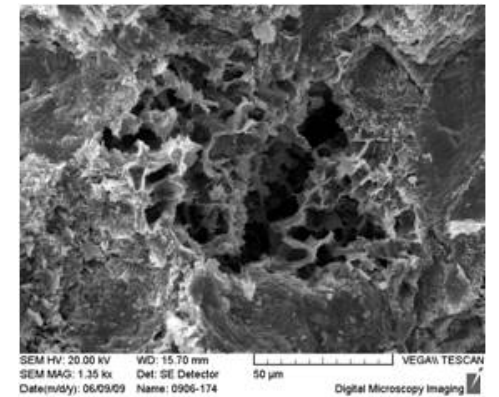

(c) honeycomb I / S mixed-layers in intergranular dissolved pores 
Dissolution plays a very important role on the improvement of the reservoir properties in this area. The dissolution can be expressed as the dissolution of the debris particles (Figure 3 (a)) as well as cements (Figure 3 (B)) and heteroaryl (Figure 3 (c)), which is very benefit to the formation of reservoirs, so also known as constructive diagenesis.

\section{Fracturing}

Fracturing is the phenomenon that rocks rupture resulting fracture porosity role under external force during the procession of diagenesis. In both the research on the core of the purpose layers and the observation of casting thin sections, sandstone fracture development (Figure 3) can be seen, which to a certain extent improved, the permeability of the reservoir. When observing core and thin sections, you can see various cracks, containing visible tectonic fractures and micro-cracks that can be seen only under a microscope. The development of these cracks plays an important role in improving the physical properties of reservoir sandstones, also contributes to strong heterogeneity of the reservoir sandstones in Chang 6 this area.

\section{Sequences of reservoir diagenesis}

According to the analysis above on the diagenesis and authigenic minerals causes, and combined with all kinds of diagenetic phenomenon under the microscope, we analyzed the diagenetic sequences. Details are as follow:

(1)Chlorite-based clay minerals cover the surface of particles as thin film of equal thickness. Few quartz particles surrounded by a clay membrane are secondary enlarged, meaning that clay film formed earlier than authigenic quartz, and was early diagenetic deposition.

(2)Parts of quartz overgrowths are replaced by calcite, and calcite cement can be seen in feldspar dissolution pores, so the calcite precipitation is later than quartz overgrowths and dissolution of feldspar grains.

(3)Calcite cement is fined crystalline, and part of it has recrystallized into crystalline. It's common that iron ankerite rhombohedral replace calcite, showing that iron ankerite formed after calcite.

(4)Therefore, based on the above analysis, we can determine the diagenetic sequence of reservoirs in Chang 6 of Baibao area: mechanical compaction $\rightarrow$ early clay membranes form $\rightarrow$ quartz overgrowths $\rightarrow$ microcrystalline calcites precipitate $\rightarrow$ sparry calcites precipitate $\rightarrow$ feldspars and calcite cements are dissolved $\rightarrow$ he calcites precipitate $\rightarrow$ alcites are dissolved $\rightarrow$ the late stage iron dolomites are filled in. According to the diagenetic stage division plan $[4,5]$ and the corresponding symbols, we divided the diagenetic stage of the study area. Taking all the diagenetic indicators into consideration, according to the the sandstone cast thin section observation and analysis under scanning electron microscopy, we can conclude that sandstone in Baibao area Chang 6 formation, should be in middle diagenetic stage B period.

\section{Acknowledgments}

The authors gratefully acknowledge financial support from The National Basic Research Program (973) of China (No.2013CB228000) and Chinese State Municipal Science and Technology Project (No.2011ZX05018).

\section{Reference}

[1] Hao Shiyan, Li Dan. Northwestern Geology Vol. 38 (2005), p.94. In Chinese

[2] Zheng Rongcai, Wen Huaguo, Han Yonglin, et al. Journal of Chengdu University of Technology (Science\&Technology Edition) Vol. 33(2006) , p.566. In Chinese

[3] Zheng Rongcai, Wamg Changyong, Li Hong, et al. Lithologic Reservoirs Vol. 19(2007), p.32

[4] Zhang Luqi, Chen Gongyang. Lithologic Reservoirs Vol. 21(2009), p.75

[5] Liu Linyu, Chen Gang, Liu Yiqun, et al. Acta Sedimentolog Ica Sinica Vol. 16(1998), p. 97 